\title{
6 The politics of feminist translation in water management
}

\author{
By Bernadette P. Resurrección and Rebecca Elmhirst \\ In conversation with Seema Kulkarni and \\ Margreet Zwarteveen
}

Feminist encounters with technical water professionals such as, for example, engineers, modelers and bureaucrats bring into view fundamental questions and differences in approaching and understanding the use and management of water. In the field of irrigation, technical water professionals are trained to conceptualise and model water systems with the goal of optimising water productivity for agro-industrial purposes. By contrast, feminist researchers are more concerned with the power-laden ways water is allocated, noting that water gives life and is part of the world's 'commons'. They explore how water can be accessed and distributed more fairly and decision making could be more inclusive. They therefore emphasise questions of social justice in relation to water's multiple uses and stakeholders.

In conversations with Seema Kulkarni and Margreet Zwarteveen - who are feminist researchers and activists in rural waterscapes - they share about how they have tried engaging technical water professionals and bureaucrats in transformative forms of feminism. They explain how these attempts are marked by a distinctive knowledge politics, as among others manifested in contrasting water use ontologies: those of water productivity and efficiency on one hand, and those of justice and equity on the other. These contrasts and the knowledge politics through which they are played out mean that relationships between technical water professionals and bureaucrats and feminists always require translations. In the conversation, they consider how to best engage in and navigate the politics of these translations. In their experience, the oft-used tactics of calling for 'integrating' or 'including' gender issues in water policies and projects is not the most fruitful pathway, despite the many 'success stories' disseminated by development donors based on the assumption of synergies between water resource improvements, gender equality and women's empowerment. In the experience of Seema and Margreet, integration of gender in existing projects or calls for more participation of women in existing water decision-making processes and bodies may create dangerous distortions and dilutions of feminist and social justice concerns. Instead of integration or inclusion, a strategy of cautious juxtaposition that 
consists of conscious strategies to learn to acknowledge differences and disagreements may be more promising.

\section{Personal and professional identities}

Our starting point in this conversation is our own positionality stemming from our own work on gender in rural waterscapes. Seema and Margreet have worked on and in irrigation in South Asia and elsewhere, with Seema having a particularly long experience in Maharashtra. Both of them have been involved in different projects to address gender inequalities or include women in irrigation projects. In talking to them, we note different places of feminist engagement with watery concerns. Where Margreet has been particularly engaged in dialogues in universities with technical colleagues and irrigation specialists; Seema has had most interactions and negotiations with local water authorities and has a lot of experience in directly engaging with landless and scheduled caste women and men. It is clear that the dominant terms in which the use and management of water is conceptualised in professional irrigation contexts are those of efficiency and productivity. A main pre-occupation of many irrigation professionals is the avoidance of waste with waste often being defined as all water that does not enter into a market equation, or that flows into the sea without being useful to man (see Gilmartin, 2003). According to Seema and Margreet, the challenge of navigating and transforming this conversation into more feminist directions importantly consists of raising the importance of questions of justice and equity, which necessarily also entails rethinking and re-defining the meanings and values of water. How to best do this importantly depends on the issue at stake, and always is itself an engagement with power.

Seema: I have been active in the rural women's movement in India since the 1990s. I prefer not referring to myself as a gender professional since to me the term originates in and represents a distinct donor-driven development agenda, one that tends to render 'gender' into yet another problem or deficiency that can be fixed through technical expertise. I instead belong to a generation of feminists whose work is anchored in and inspired by direct engagements and interactions with rural women, for whom water was and is a major concern. Currently, I work for SOPPECOM, an organisation working primarily on land and water issues. SOPPECOM started out as a multidisciplinary team with engineers and social scientists working and thinking together. SOPPECOM is committed to advancing the agenda of social justice in water, with a clear focus on gender and caste issues.

In my work, I start from an identification with the lived experiences of women and from a deep understanding of their social contexts. Much of my work consists of trying to trace the likely impacts of macro policies on their lives. Hence, we collect vital information on women's work, also in agriculture - such as weeding, threshing, etc. - we document gendered patterns of land access and ownership, and highlight the importance of women's 
knowledges in such things as seed conservation, etc. All this helps us in understanding the irrigation conditions, such as the functioning of the irrigation system, its current users and members, and the gender and caste composition of the members and users. In a nutshell, whereas the technical team might be more interested in the technical performance of the irrigation system and the health of the canals, we would also like to understand the use of the system and its users: and this is where understanding gender relations is important.

Babette: I've been a researcher on gender and environment now working more within interdisciplinary teams on energy transitions and finding ways how this could work. I struggle with the emerging research approaches today that favour more positivist knowledge than embodied knowledge even among social science researchers and its privileging among development practitioners.

Becky: I come from an academic background in human geography, where my research on gender and environment has been heavily informed by fieldwork concerning forests and rural livelihoods. Being based in a university, where most of my time is spent teaching the next generation of gender and environment researchers, I'm interested in how apparent gaps between critical feminist theory and gender and development practice are reconciled (or not) in environmental science contexts.

Margreet: In 2014, I joined IHE-Delft, an Institute for Water Education and I am also affiliated with the University of Amsterdam. At IHE-Delft, I work with natural scientists and engineers focusing on different water questions. I am responsible for the small but rapidly growing social science corner in the Institute. In the course of my academic career (which started in 1997), I've done a lot of work on water, often on issues of equity and justice, and often through the entry point of gender with an explicit feminist commitment. I have come to appreciate how much of this work consists of creating the spaces to discuss radical and often oppositional feminist ideas, often translating them to make them palatable as well as actionable to those working in water.

I was trained as an irrigation engineer, but during my MSc studies I chose to divert from the normal engineering curriculum to take courses in Development Economics, Anthropology, Gender Studies etc. Much of this was prompted by a deep interest to understand how changes in (access to) water and changes in social relations co-constitute each other. Even while I never felt myself to be a 'real' engineer (whatever that may be), my basic training and background as an engineer was and is useful in establishing some credibility with my colleagues and wider peer group when working on water.

I am not sure whether this background has helped my credibility as a socalled gender professional as this very much depends on who is asked. As I always worked between and across disciplines, those colleagues who invest pride and derive status from belonging to one discipline sometimes question whether I 'belong' to the engineering profession or whether I am either a 
'true' social scientist or engineer. I myself try to steer clear from such status battles, and aspire to publish in geography, development studies and social sciences journals as well as in water and environmental science journals. At the same time, I am very much aware how my own authority and influence for instance in creating space in professional water domains for questions of gender justice - also depends on my ability to mobilise and assert disciplinary forms of authority.

Some contributors to other chapters in this book indeed highlight their "crossovers' from their technical backgrounds to undertaking gender-focused research and interventions in different environmental and resource contexts. And like Margreet above, they too strategically use their disciplinary authority as technical specialists to legitimate attention to gender and social justice issues in highly technical working environments.

\section{Feminists, gender experts and women engineers}

Margreet and Seema are concerned that the inclusion of gender experts and expertise in water development programs stimulated by global water agreements may neutralise, instead of advance, a more political and feminist gender and water justice agenda. This is because a mandate for transformative feminist change intrinsically entails questioning accepted knowledges and related positions, identities and hierarchies. Indeed, addressing gendered inequities in the technical environment of the water sector importantly includes the critical scrutinising of established epistemological normalcies as well as the questioning of normal ways of diagnosing problems or proposing solutions. Beyond merely including women or gender, therefore, addressing questions of gender (in-)justice requires the cautious navigation of political and epistemological tensions. Feminists hardly ever have enough political leverage to simply demand or order what needs to happen, which is why they need to find ways to convince those with more power to follow their recommendations even when those are unsettling. In water, this implies being able to talk the language of engineers and understand and empathise with their pre-occupations (see for example, Udas \& Zwarteveen, 2010). Doing this always carries the risk of too much identification with the engineering or technical project of efficiency or productivity, to the neglect of the goals of justice and equity.

Women engineers, for their part, may not be taken seriously by their male peers. According to Liebrand \& Udas (2017), for them to succeed and belong, they have to reconcile the performances of being a 'lady engineer' with that of a 'normal' masculinised engineer, which may be asking for the irreconcilable. This brings to fore how feminist politics in water contexts also involves becoming aware of, navigating and contesting prevailing identity boundaries. This points to the difficulty for women to credibly perform as engineers, and it points to epistemic hierarchies in water professional contexts between social sciences and natural sciences engineers. Gendered professional identities directly matter here, as in water those who are generally attributed most authority are male engineers. For 
social scientists, let alone gender specialists or feminist scholars, it may be difficult to be seen and treated as sources of expertise.

Kunz et al. (2019) point out that gender experts as social scientists may cope with such hierarchical and political tensions by 'erasing the boundaries' between gender expertise and the positivist sciences to realise more pragmatic and technical outcomes. This may lead to de-politicising gender and water agendas to a significant extent.

Margreet: I am getting many requests to do gender related work in water projects supported by development cooperation funding. In these projects, gender often risks becoming a mere 'technical' issue, one that is totally de-politicised. Development projects place a lot of emphasis on success stories, best practices and solutions. The associated language may not be helpful in realising feminist goals, because feminism intrinsically is a process and a struggle, and not something you can achieve in a project of 4-5 years. Contemporary water projects for instance emphasise the potential of new irrigation technologies - such as drip irrigation - in helping farmers become entrepreneurs. In this storyline, farmers - either female or male - figure as individual businesspeople who are constrained in reaching their potential because of their limited access to technologies, markets or finance. The gendered version of this story line is that women face even more constraints than men, resulting for instance in prognoses of what production could be if women would have the same access to land, water, technologies and much else as men. There is much to be said against this story line, but what matters when examining it from a feminist lens is that small-scale irrigated farming - almost everywhere in the world - is a family affair in which men, women and children all collaborate, often following historically and culturally distinct ways of distributing responsibilities, rights and incomes. It therefore makes little sense to treat women or men as individual farmers, or to compare men's productivity with that of women: farming is a collective matter, and understanding it requires an understanding of the intra-household organisation of agriculture.

Discussing this with donors and those who believe in the story of the individual farmer-entrepreneur is difficult. That is the field of tension that I find myself in. And I'm trying to navigate, and I don't always find it easy.

Margreet and Seema both distance themselves from self-identifying as gender experts since they believe that being so ties them to mainstream development agendas that do not fully seek to understand women and men's lived experiences with water systems. Margreet, in particular, observes the work of gender experts as sometimes removed from the very contexts they are trying to change.

Becky: Would you say then that gender experts have engaged in a so-called 'technocratic compromise'? One of the contributors to this book said, 'Well, bring them to the field so they can see. The complexity can be demonstrated.' Maybe you have other thoughts to add to that? 
Babette: That's good of you to recall, Becky. But at the same time, we're also facing the dilemma of how we can use the development space for opportunities? Or should we actually just wish them away and say, 'No, we refuse to be co-opted by the development process since it blurs our feminist and justice agenda.' And a number of development organisations and donors today support the work of gender experts and it is part of their institutional mandate to ensure they are an integral part of programmes.

Margreet: My experience is that often, development donors and implementers are under pressure to demonstrate success, something they can do by suggesting direct causal relations between interventions and positive outcomes for women or gender equity. The dynamics of power and politics that characterise feminist transformations are difficult to capture in causalities and outcomes, as these refer to processes of struggle and contestation in which winners and losers are not always easily determined, with cause-effect relations that are less straightforward and multi-dimensional. This does not mean that when I am asked to contribute to making water policies or projects more gender aware or inclusive, I refuse. I do sometimes accept because of the possibility to positively engage with planned changes or interventions. And then in the process, also ask some of the more difficult questions. So that's now becoming my strategy.

\section{Water productivity, state reform and the water profession}

Seema has contributed to knowledge on gender and water reforms in the Indian context by highlighting the missed opportunity that decentralisation provided to democratise water governance through a policy of non-engagement with social and feminist movements with alternative knowledges and cultures of water management (Kulkarni, 2011, 2016). She also demonstrates how far from reaching their inclusive ends, reforms around privatising groundwater and sanitation infrastructure have increased gender and social inequity, environmental risk, and gender-based violence (Srinivasan \& Kulkarni, 2014; Kulkarni et al., 2017). Seema's continuous engagements with policy makers and NGOs have become seamless with her own research pursuits especially exploring the meanings attached to water use.

Margreet: I am always inspired by Seema's work in Maharasthra with the Irrigation Department, working in the program around increasing participation of water users, and using that to increase spaces for poor and landless women.

Seema: We are working with a techno-centric and male-centric irrigation department. In the 1990s, we were lobbying at the policy level and advocating the irrigation bureaucracy to include women in water user associations-local level institutions formed for better participation of farmers in surface irrigation systems. Gender experts were unheard of then. The irrigation bureaucrats were not prepared to talk about issues around landless women and 
water. They had their typical parameters and indicators to judge the success of the irrigation system's performance, i.e., how much crop per drop of water! The irrigation bureaucracy's response to our advocacy was to ask how women and landless people's participation was going to improve irrigation performance, which usually referred to how much water was served on a plot of land for crop productivity. They could not see beyond these parameters. They could see the roles of women and landless groups only insofar as these could improve irrigation performance, which was a very narrow and straightjacketed view.

Their ways of thinking did not allow them to take the broader view of people, particularly the role of marginalised people. At that point, we realised we needed to change our ways, we needed to say things differently. We needed to help them see that there's a need for a more just world. This process of change - with a lot of support from global normative discourses - helped raise awareness in the government. Since 1995, they have gradually begun to see gender in the water question.

The outcome was bringing in women and marginalised groups under the policy [legal reform] and decision-making bodies. This meant that they do recognise their roles. I know we need to go beyond representation, but what's happened is a really big step forward. Yes, representation is necessary, but that is not sufficient. There have to be commitments that representation should lead to broader outcomes - just water practices. There was a lot of learning among communities too. We still have a long way to go helping bureaucracies recognise the politics of gender and water. I think it unfortunately has not moved beyond representation and quotas. Within irrigation water user associations, there is representation of women. For domestic water, there would be village water and sanitation committees. These are local level formations. State-regulated structures are federated with water distribution from dams and canals to the irrigation project level. Irrigation would have project boundaries not administrative boundaries. So, there is representation of these groups in these committees. But in the profile and composition of the bureaucracy itself and in the technical jobs and the hierarchies, you will not see women or marginalised groups represented. It is only because of the quota system for caste that we see some appointments of marginal groups. There is an absence of women at the top positions in water bureaucracies.

The discourse of 'water for productivity' is also changing. Over the decades, organisations like ours have changed the discourse such that it is no longer politically correct to make that distinction between productive and non-productive uses of water, although the mindset on productivity is still very strong. There is a greater recognition now of the multiple uses of water. A very generic water policy document will state that, but there's little buy in. But when you look at the programmatic documents and actual allocations, you again see that they're largely channeling water for paying sectors. In that sense, industry gets the priority. It still is predominant, but whenever there is pressure, it is no longer easy for bureaucracies to get away with that 
kind of talk [the productivity argument]. Shifting the mindset is an ongoing challenge, nevertheless.

On the subject of water productivity, Margreet, for her part, wonders why this is a prevailing mindset among water professionals.

Margreet: What I find very odd, working on water as a feminist, is that the predominant language used by my water colleagues is a language of productivity and efficiency: it's about the dollar per drop of water. As feminists, we use the language of justice, of equity, one that allows recognising the sharing and care for water. My water accounting colleagues use remote sensing data water maps that are in theory accessible and legible to many, and thus could be mobilised in support of improving water democracy in theory. But if the maps only show water productivity, what kind of water futures do they support? So sometimes I ask my colleagues, can we not have 'water happiness or wellbeing maps' instead of only making water productivity maps? We're only starting these discussions. It requires so much patience to actually sit together and understand each other.

\section{Living with technical and social incongruities in water management}

There is increasing concern over a prevailing type of rational environmental governance where epistemic authority is vested on mathematical and statistical abstractions in the form of statistical indicators, modelling, imaging technologies and risk assessment exercises (Wang, 2015). This is an effort to render 'unruly' nature (e.g., water, climate and forests) intelligible, ascribe it with more certainty, and therefore depict it as more amenable to control, prediction and management. This technical 'evidence-based' approach has been popularly used to premise key policy decisions, which, however, deflects attention from the drivers of inequality and disadvantage ( Eyben, 2013; Bacchi \& Goodwin, 2016; Eriksen et al., 2015; Taylor, 2014). In contrast, Margreet and Seema's corpus of work has been dedicated to disrupting such efforts by showing how prevailing ways of measuring and accounting for water only make some characteristics or capacities of water visible - such as those aligned with colonial discourses of avoiding waste and improving efficiencies - at the neglect and expense of injustice and exclusion issues. In addition, scientific conventions of measuring water treat it as if it can be disconnected from social relations and histories - relations of labour and property, most notably - which, as a result, also make it impossible to see water as deeply connected to and constitutive of societal orders. Questions of gender inequality, patriarchy, and injustice therefore remain very difficult for water scientists and professionals to recognise and tackle.

Prevailing scientific and professional ways of knowing and conceptualising water are themselves the legacy of particular colonial and patriarchal structures. Margreet has scrutinised masculinity in the irrigation and engineering profession 
by unpacking its cultural, material and performative elements and highlighting processes of masculinity's normalisation and naturalisation; citing masculinity as a product of the diffusion of colonial and professional water knowledge that remains persistent; showing that to be an engineer is to embody masculine qualities such as scientific rationality and positivism, technological prowess and physical hardship; that the engineering sciences have an almost stubborn propensity to bracket out knowledge on gender and social relations; and how water rights have been conventionally narrowly defined as male-controlled due to fewer possibilities for women to own land and other vital resources that mediate water rights (Alda-Vidal et al., 2017; Delgado \& Zwarteveen, 2017; Zwarteveen; Zwarteveen, 2008, 2010, 2011, 2017; Zwarteveen \& Rap, 2017; Zwarteveen et al., 2012). These ideas rally around a key theme in this book that suggests gender, power, knowledge and professions are indeed co-constituted.

Becky: One of our contributors said that they found it easier in some ways to engage with some of the technical people who had a background in agricultural systems or in rapid rural appraisals as they'd done field-based work, which necessarily meant working with people. I don't know whether the same could be said in the water sector or if there's something specific about water and its connection to engineering that means it's sometimes quite disconnected from the field or at least from voices in the field. Does this make it difficult to negotiate and find a common language around social issues?

Margreet: Yes, I think that's a very good point, Becky, because I remember years ago when I was working with the International Water Management Institute (IWMI) where at that moment we had the conversation across different international agricultural research centers about how to do gender, or how to make more space for gender. And the consensus seemed to be that participation was the entry point: participatory approaches to development. And I thought, well, water participation seems nice. It's a good entry point. But over the years, I have come to think that often questions of participation and decision making do not touch on wider allocation or distribution questions. So, I also felt we are missing out some of the more fundamental questions if we approach it from the angle of participation.

And you're also right, I think that engineers are not wired to diagnose problems, but their minds are wired to propose and design solutions. So that bringing them back to consider what problem a particular solution will help solve is a difficult step to make. Because for them, it feels like going backward to what the problem is. For them, it's all a matter of 'let's get on with it!' That's a comment that I often hear. Because when you want to do gender, actually you need to make that step back and rethink, 'Hey, but what is the problem? Can we rethink it?'

Babette: Or maybe - correct me if I'm wrong - because engineers actually define the problem in very technical terms, such as: 'Oh, there has to be a bridge somewhere or some infrastructure that's needed.' 
Margreet: Yes. But so that is not even defining a problem, it's defining a solution. It's proposing a solution to a problem that is supposed to be already diagnosed or identified or known.

In her own earlier writing, Margreet says that 'unwillingness or persistent biases of individual water analysts, the difficulty to see women and gender in water is linked to a particular epistemic tradition in knowing water that is deeply inhospitable to the analysis of social relations and gender. An important conclusion is that "thinking" (and acting on) gender in water management also and importantly requires active efforts to change normal ways of knowing in water' (Zwarteveen, 2010: 75).

Babette: I ask myself constantly why it is difficult for engineers and modelers to link gender issues with their work. This was especially true when I was teaching in a predominantly engineering university. The only option was for us gender researchers to work separately from the engineers. It may be because their worldview is different, and perhaps their methods too. We existed in ontological and epistemological silos. And that created an uneasy peace. Now working in a different organisation that is open to inter and transdisciplinary work, I am pleased to find water modelers who are excited to integrate gender into their work. However, they are limited by the scarcity of gender-disaggregated data in water systems, so their recourse is to confine gender concerns to including women in stakeholder engagement. I wonder whether it is just a matter of acquiring gender-disaggregated data - which in their view achieves gender integration - or whether it is a matter of different types of knowledge. I must confess that I need to know and understand modelling more to know how and where the useful entry points for gender are. Or maybe I suspect there are no entry points, especially since their approach is disaggregation, that is, to count women and men; whereas our research approach is to understand embodied experiences.

Margreet: In modelling, all kinds of assumptions are made about which descriptors to use for representing a reality. In water, a very basic assumption that often goes into modelling is a normal natural science assumption: that it's possible to somehow compare waters across many different places. This requires making abstractions about water that always exclude social dimensions. Once the model is used for decision making - it will have to be recontextualised - and so there, gender can matter, but it's often not included in the re-contextualisation.

Some of our conversations (on epistemology) have led to fights. They (modellers) are working from a positivist perspective. As a social scientist, we use more constructivist, non-modernity approaches. I realise that it's almost impossible to bridge these two different ways of knowing. But I think it is possible to start the dialogue by asking whether there are other ways of representing water (other than for productivity), or to model for different water logics. I felt it was a bit easier to start with the question of logics than 
with the question of knowledge, because with the knowledge question the modelers felt that I was telling them that they were not being objective. In a way, that's how they understood it, but I told them that it was not meant as a criticism. What I wanted to say to them was that none of us are objective, at least not in the conventional or popular use of the term. But that was just one step too far for them.

Babette: Interesting. And I think this brings us to the next point, which is really about different and multiple knowledges in relation to studying and managing water. Are there better ways for the technical and the social to co-exist? We often invoke the positive outcomes of interdisciplinarity or even transdisciplinarity and the need to work with cognate fields. Maybe it's better to think not in terms of integrating knowledges, but really 'juxtaposing' knowledges or a kind of 'triangulation'? That's a thought I want to sort of just throw in.

Researchers conventionally use triangulation as a methodological approach to ascertain whether the data collected through one method matches the data collected through another method. It is mainly used to ensure that the data collected is reliable. This is done by collecting data using diverse methods, recognising the internal validity of each of the data sets collected respectively through such methods, but at the same time interrogating the 'silences' between the data collected, and finally recognising the limits of each method (Nightingale, 2003; HesseBiber, 2012; Harris, 2016; Nightingale, 2016). These silences allow for generating further research questions that otherwise may have been omitted or sidelined in the original research design but can potentially shed light on unexplored realities. The approach also underscores the point that feminists have been making all along: that all knowledge is partial (Haraway, 1988). It also presupposes that the research can be undertaken by researchers from diverse research and disciplinary backgrounds. Because of this, researchers have come to mine its potentials for enabling cross-learning and knowledge co-production.

In the water sector, Mukhtarov and Gerlak (2014) have come to recognise the importance of epistemic pluralism in addressing the challenges of water management that are far too complex for the prescriptive nature of integrated water resource management. Their work draws attention to the co-existence and versatility of multiple knowledges that go beyond the idea of triangulation as a methodological approach and recognise the need to capture and interrogate diverse knowledges in water contexts.

Margreet: I like the idea of triangulation a lot. For a long time, the MSc program on water management at the IHE was partly implicitly based on the idea of integrated water resource management. So, the idea of integration became very central to the whole program. Triangulation may help re-think what integration implies and does. The idea of integration actually suggests that it's possible and desirable to bring all different knowledges together into one big whole, a uni-verse. This may not be the most fertile idea, as different knowledges and ways of knowing cannot always be easily added up or integrated: 
there are resonances, but also frictions, clashes and indeed silences. So, what we are now experimenting with, is rather than integration, use some idea of plurality linked to controversies. Rather than making integration and harmonisation the guiding ideas and implicit ideals, our attempt is to direct attention to plurality, difference and contestation. By acknowledging differences of interest, differences in diagnosing problems, different solutions it becomes possible to accept that perhaps there is not one world, a uni-verse, but there are many possible worlds, a pluri-verse. I don't know whether that is what you mean with triangulation, but if it means creating room for different ways of knowing and different versions of reality to co-exist I am all in favour.

Babette: But what seems to be quite mainstream up to now is the integrated water management approach. And do you think there are opportunities perhaps to realise an altogether new agenda for water management, given this need to juxtapose, differentiate, rather than integrate?

Margreet: I would hope that in triangulation, we would also be learning to disagree and accept that there are differences that are sometimes very difficult to reconcile. And of course, compromises need to be made if you need to arrive at a practical solution. But there are always differences of interests, contestations and conflicts that the word triangulation may better allow to acknowledge, whereas the word integration entails an active invitation to forget about those by focusing on consensus or collaboration. Resolving irreconcilable elements is always a practical and political concern, as much (or more) as it is a scientific one.

Becky: One of the issues we explored with other contributors was the politics of knowledge. It is actually also about who is setting the terms of the dialogue because some forms of knowledge are dominant in those exchanges. It's like gender. People are invited in to do the 'gender work'. But, actually, they're not really driving the wider agenda or even dialoguing on the wider agenda, or indeed setting the initial terms of the debate. I suspect that quite a lot of them are invited but not on their own terms.

Seema: Yes. It is really only worthwhile when there is an opportunity to dialogue, but obviously not where one or the other is sort of dominating the terms of that dialogue. So, if it is an open process of dialogue between the technical and gender professionals, I think it's worthwhile to have.

Margreet: I have come across many water projects that have hired people to do 'gender' in their projects. Sometimes their most important qualification for being hired was that they were women. What I have seen happening and what still happens is that these gender professionals are put in a position where they continuously have to explain and defend what they do; why attention to women and gender is important. One dangerous strategy that some of them resort to is to approach gender equity as primarily a moral or ethical position, something that belongs to either individual integrity or that is an indicator of 'development', with an idealised and non-existing gender equality in western countries figuring as the implicit norm that others should follow or adhere to. I have seen very awkward situations where white, western 
gender professionals preach to for instance Nepali or Indian irrigation engineers on how they should deal with women or gender in the water projects they are professionally involved in. Awkward not just because of how these gender awareness trainings make often wrong assumptions about what these engineers think about and how they deal with questions of gender, but also because of how they misrecognise the few real practical possibilities that engineers have to address questions of gender equity in their work. Gender equity of course always is an ethical or moral question, but it is also a practical and political one and one that always transcends water. Therefore, what gender equity is or should be cannot be formulated on the basis of abstract ideals but needs to be anchored in grounded gendered water experiences and histories. Engineers working in the field always do have knowledge about gender relations, and this knowledge should be the basis for engaging in discussions about what they can or should do. I think that gender is so complex, and it's only by allowing people - both irrigators and water users as well as engineers - to speak for themselves that one can start having meaningful conversations. I therefore also think one is in a much better position to do gender work with technical water professionals if one understands, acknowledges and respects what they are doing.

Babette: Would gender experts or feminists on the ground need to know something about engineering? And if they have social science backgrounds, would it be necessary for them to have skills to deal with the technical?

Margreet: Yes, I think so. You don't have to be an engineer, but you should have some respect for the work that the engineers are doing. I think Seema is always saying that there seem to be very few good social scientists interested in gender and water. At the same time, if the context in which you work is a very technical one like the one I found myself in the International Water Management Institute in the 1990s, you are continuously pressured to translate between different languages. I don't know whether you need a technical background but, at least, you need to learn how to do this translation. And you also need to start understanding what gets lost in the translation.

Seema: I agree generally with Margreet but I also think that the reverse is true. I mean, you also need technical people with an understanding of the social questions, I would say, a sensitivity to it, and also the need to see the interface between technology and society, which, unfortunately, is very, very lacking in the context that I am working in actually. And I also feel that the burden for people like us who are talking about social justice, differences, and discrimination, to understand the technicalities of water is much more, because we have to know the sector extremely well to be able to see and argue in a very firm manner, to show that there is discrimination, and in what possible ways we could address it. So, I think the burden is much more on people like us (social scientists/practitioners). It is possible for the water agenda to move forward without having to address any of these social or equity concerns. For example, transboundary issues, or questions around agriculture versus industry, contestations between various uses of water. I mean, even if you 
don't say a word about gender and social relations, that agenda still moves ahead, pretty much, and very easily. But the same is not true if I'm only going to say 'gender, gender, gender', it will completely be in a vacuum, and I'm never going to be heard. So I know that I have to be very thorough with my understanding and knowledge about transboundary water issues or contestations in this terrain, if I want to be heard on questions of social difference. We have to reach the stage where people who are looking at the technical aspects, or I would say even people from social sciences but who don't really look at social discrimination and social justice have to be sensitive, and educated enough to say, 'No, the agenda cannot move forward if we have not understood the question of social difference'. A two-way exchange is very, very strongly needed. Because I have seen that we have just been silenced out in discussions around, for example, drip irrigation. As if there is no social agenda that exists, it's just a matter of putting those systems in place. So the burden was much more on advocates like us who then had to make sure that we understood drip irrigation, its technology and its implications on questions of allocation and access.

\section{To conclude}

Our analysis suggests that the incentive structure and professional culture that prevails in most public water bureaucracies stands in the way of achieving the goals of women's inclusion or empowerment. Public water professionals - the large majority of whom continue to be engineers and men - are formally rewarded and informally appreciated for the construction work that they do, or for the number of the projects they are involved in. Professional engineering cultures tend to naturalise or normalise associations between professional performance and masculinity, making it difficult for women to become respected members of the professional water community. The gender experts in water development projects often lack the political clout to change the terms of dialogue with their technical colleagues, as their work is often considered marginal to the main task of achieving water productivity.

We end this discussion with the view that there are different and hierarchical ways of knowing in the water sector, where epistemic privilege mostly still lies in creating physical and institutional conditions for water productivity to serve market-driven ends, rather than for purposively democratic and gender-just water distribution. Integrated water resource management has served as a popular vehicle to merge these types of knowledge and tie them to a strong participatory ethic. Years of observing the application of these approaches through the creation of water user and other water subsidiary groups have led us to conclude that just and re-distributive aspects of water continue unaddressed. Indeed, there may be a need to re-think the widely used view of 'integration' and shift instead to recognising the constancy of irreconcilable difference and contestation around water as a resource - or even better, seek more creative and promising ways of co-producing knowledge that recognises that there is more than one way of knowing. 


\section{References}

Alda-Vidal, C., Rusca, M., Zwarteveen, M., Schwartz, K., \& Pouw, N. (2017). Occupational genders and gendered occupations: The case of water provisioning in Maputo, Mozambique. Gender, Place \& Culture, O(0), 1-17. https://doi.org/10.1080/0 966369X.2017.1339019

Bacchi, C. L., \& Goodwin, S. (2016). Poststructural Policy Analysis: A Guide to Practice. Palgrave Macmillan.

Delgado, J. R. V. \& Zwarteveen, M. (2017). Queering engineers? Using history to re-think the associations between masculinity and irrigation engineering in Peru. Engineering Studies, 22.

Eriksen, S. H., Nightingale, A. J., \& Eakin, H. (2015). Reframing adaptation: The political nature of climate change adaptation. Global Environmental Change, 35, 523-533. https ://doi.org/10.1016/j.gloenvcha.2015.09.014

Eyben, R. (2013). Uncovering the Politics of 'Evidence'and 'Results': A Framing Paper for Development Practitioners. Prepared for the Politics of Evidence Conference in Brighton, UK.

Gilmartin, D. (2003). Water and waste: Nature, productivity and colonialism in the Indus Basin. Economic and Political Weekly, 38(48), 5057-5065.

Haraway, D. (1988). Situated knowledges: The science question in feminism and the privilege of partial perspective. Feminist Studies, 14(3), 579-599.

Harris, L. M. (2016). Intersections of gender and water: Comparative approaches to everyday gendered negotiations of water access in underserved areas of Accra, Ghana and Cape Town, South Africa. Journal of Gender Studies, 1-22. https://doi.org/10.1 080/09589236.2016.1150819

Hesse-Biber, S. (2012). Feminist approaches to triangulation: Uncovering subjugated knowledge and fostering social change in mixed methods research. Journal of Mixed Methods Research, 6(2), 137-146. https://doi.org/10.1177/1558689812437184

Kulkarni, S. (2011). Women and decentralised water governance: Issues, challenges and the way forward. Economic and Political Weekly, 46(18), 10.

Kulkarni, S. (2016). Gender and water in India: A review. In V. Narain \& A. Narayanamoorthly (Eds.), Indian Water Policy at the Crossroads: Resources, Technology and Reforms: Vol. Global Issues in Water Policy (pp. 73-91). Springer International Publishing.

Kulkarni, S., O'Reilly, K., \& Bhat, S. (2017). No relief: Lived experiences of inadequate sanitation access of poor urban women in India. Gender \& Development, 25(2), 167183. https://doi.org/10.1080/13552074.2017.1331531

Kunz, R., Prügl, E., \& Thompson, H. (2019). Gender expertise in global governance: Contesting the boundaries of a field. European Journal of Politics and Gender, 2(1), 23-40. https://doi.org/10.1332/251510819X15471289106112

Liebrand, J. \& Udas, P. B. (2017). Becoming an engineer or a lady engineer: Exploring professional performance and masculinity in Nepal's Department of Irrigation. Engineering Studies, 9(2), 120-139. https://doi.org/10.1080/19378629.2017.1345915

Mukhtarov, F., \& Gerlak, A. K. (2014). Epistemic forms of integrated water resources management: Towards knowledge versatility. Policy Sciences, 47(2), 101-120. https:// doi.org/10.1007/s11077-013-9193-y

Nightingale, A. J. (2003). A feminist in the forest: Situated knowledges and mixing methods in natural resource management. ACME: An International Journal for Critical Geographies, 77-90. 


\section{Feminist translation in water management}

Nightingale, A. J. (2016). Adaptive scholarship and situated knowledges? Hybrid methodologies and plural epistemologies in climate change adaptation research. Area, 48(1), 41-47. https://doi.org/10.1111/area.12195

Srinivasan, V. \& Kulkarni, S. (2014). Examining the emerging role of groundwater in water inequity in India. Water International, 39(2), 172-186. https://doi.org/10.1080/0 2508060.2014.890998

Taylor, M. (2014). The Political Ecology of Climate Change Adaptation: Livelihoods, Agrarian Change and the Conflicts of Development. Routledge.

Udas, P. B. \& Zwarteveen, M. Z. (2010). Can water professionals meet gender goals? A case study of the Department of Irrigation in Nepal. Gender \& Development, 18(1), 87-97. https://doi.org/10.1080/13552071003600075

Wang, T. (2015). Green governmentality. In R. L. Bryant (Ed.), The International Handbook of Political Ecology (pp. 318-331). Edward Elgar Publishing.

Zwarteveen, M. (2008). Men, masculinities and water powers in irrigation. Water Alternatives, $1(1)$.

Zwarteveen, M. (2010). A masculine water world: The politics of gender and identity in irrigation expert thinking. In R. Boelens, D. H. Getches \& J. A. Guevara Gil (Eds.), Out of the Mainstream: Water Rights, Politics and Identity. Earthscan.

Zwarteveen, M. (2011). Questioning Masculinities in Water, 18, 10.

Zwarteveen, M. (2017). Hydrocracies, engineers and power: Questioning masculinities in water. Engineering Studies, 9(2), 78-94. https://doi.org/10.1080/19378629.2017.13 58730

Zwarteveen, M., Ahmed, S., \& Gautam, S. R. (Eds.). (2012). Diverting the Flow: Gender Equity and Water in South Asia. Zubaan.

Zwarteveen, M., \& Rap, E. (2017). Guest Editor's Introduction: Engineering masculinities in water governance. Engineering Studies, 9(2), 75-77. https://doi.org/10.1080/193786 29.2017.1363019 